\title{
HAEMORRHAGIC DISEASE OF THE NEWBORN
}

\author{
BY \\ ELIZABETH B. S. SCOBBIE, M.B., Ch.B., D.C.H.
}

(From the Department of Paediatrics, Glasgow University, the Royal Hospital

for Sick Children, Glasgow, and the Royal Maternity Hospital, Glasgow)

There is a wide difference of opinion regarding the criteria necessary for the diagnosis of haemorrhagic disease of the newborn. Formerly, the essential feature seems to have been bleeding from the alimentary tract, hence the synonym ' melaena neonatorum.' More recently a wider view has been taken and many authorities do not consider that haemorrhage into the alimentary tract is necessary for diagnosis, but regard all cases of spontaneous haemorrhage from any organ or tissue, internal or external, in the absence of trauma, infection or any definite disease, as examples of the condition.

Salomonsen (1939), however, claims that the bleeding is seldom spontaneous and is almost always of traumatic origin. Capon (1932), on the other hand, excludes cases which show haemorrhage into internal organs on the ground that such haemorrhage usually results from trauma ; and both von Reuss (1921) and Capon (1932) consider that all cases in which haemorrhage occurs for the first time after the seventh day of life are caused by infection and hence exclude them. Others (Rodda, 1920; Salomonsen, 1939) consider that the basic factor is prolongation of the bleeding time or of the clotting time, or a combination of both, but Schloss and Commiskey (1911), Clifford (1935) and others have drawn attention to the fact that delay in the clotting time of the blood is not a constant feature. Recently, it has been claimed (Hellman et al., 1939; Quick and Grossman 1940: MacPherson, 1941: Salomonsen, 1939) that the primary factor is a deficiency of prothrombin which in turn is due to a deficiency of vitamin K. On the other hand the recent work of Sanford et al. (1942) throws doubt on their conclusions. Snelling (1940), Mengert (1940), Kove and Siegel (1940) consider there are at least two etiological factors, one of which is always hypoprothrombinaemia and Mengert (1940) suggests that the additional factors may be birth trauma, anoxaemia and other causes of bleeding.

Snedeker (1941) draws attention to the increased incidence of asphyxia in his series of cases of haemorrhagic disease of the newborn, as compared with the incidence in other newborn infants; in this connexion there is an interesting account by Cruickshank (1923) of asphyxial haemorrhages occurring in several foetuses whose mothers had died from concealed accidental haemorrhage before the onset of labour. He found petechial and capillary oozings in various situations, and in some instances gross haemorrhage into the viscera. Clifford (1941) described the autopsy findings in eleven infants delivered by Caesarian section before the onset of labour, in cases of placenta praevia. Intra-partum asphyxia from retro-placental haemorrhage was the cause of death in every case, and haemorrhage, along with other evidence of asphyxia, was present in all. He claims that the extreme degree of oxygen deficiency which is present in asphyxia has a direct effect on the blood vessels; it causes congestion, dilatation, escape of plasma and haemorrhage. The smaller blood vessels apparently become fragile and two types of haemorrhage may result: (1) petechial 
which is usually widespread, and (2) extensive bleeding in the lungs, liver, heart, alimentary tract and brain. As a result of detailed examination of these cases Clifford (1941) says that ' much of the gastro-intestinal, pulmonary, and liver haemorrhage may be of this origin, and that in the complete absence of trauma, asphyxia may be responsible for varying degrees of haemorrhage into the cerebrospinal fluid, into the ventricles and into the brain substance itself.'

These findings suggest that asphyxia may be a cause of haemorrhage in the newborn, but they do not afford an explanation for the bleeding in the large majority of cases of haemorrhagic disease.

Haemorrhage in the newborn infant owns many causes. Some of these, such as gross trauma and severe infection, are generally recognized not to be responsible for true haemorrhagic disease, but there are other conditions which are thought by some to play a contributory part in the etiology. The most important of these is minor trauma, insufficient in itself to lead to profuse haemorrhage, but which, when associated with some blood abnormality, is capable of producing gross haemorrhage. For example, in haemophilia bleeding will only occur when trauma supervenes. This raises the difficult question whether or not infants who have low concentrations of plasma prothrombin, and who have incurred mild trauma followed by profuse bleeding, should be classified as cases of true haemorrhagic disease. Snedeker (1941), while questioning the justification for so doing, includes cases in which this haemorrhagic tendency was revealed by such minor trauma as that caused by circumcision or by operation for tongue tie. Some authorities hold that infants with gross intracranial haemorrhage, in the absence of a history of trauma or asphyxia, should be considered as cases of haemorrhagic disease; particularly is this the case when the onset of symptoms is delayed till three or four days after birth.

The problem of classification also arises in cases where there is minor localized trauma but widespread haemorrhages. In such cases Clifford's (1935) recommendation has been adopted. He says that if in addition to local haemorrhage of traumatic origin (in the central nervous system, liver, adrenals) the infant develops spontaneous internal or external haemorrhage in areas not directly related to the injury, the case should be classified as haemorrhagic disease of the newborn. Only one case of this nature is included in the present paper (p. 177). Likewise he recommends that cerebral haemorrhage, occurring in the absence of a history of trauma, and associated with multiple haemorrhages in other areas, should be included.

Difficulty in diagnosis also arises when infection is associated with haemorrhage. It is generally agreed that septicaemia frequently causes widespread haemorrhage, and pneumonia and enteritis may be haemorrhagic in type, giving rise to considerable haemorrhage into the lung or the bowel, and in some cases to bleeding elsewhere. Such cases are clearly not examples of haemorrhagic disease. On the other hand it is questionable whether or not cases with mild and localized infections but with widespread haemorrhage should be excluded.

Lastly, there are certain conditions in which haemorrhage occurs, but which are certainly not examples of haemorrhagic disease. In a considerable pro- 
portion of cases of icterus gravis haemorrhage occurs and the picture very closely resembles haemorrhagic disease of the newborn. In a consecutive series of forty-three cases of icterus gravis admitted to the Royal Hospital for Sick Children, Glasgow, haemorrhage occurred in nineteen. When blood has been ingested during labour or from a bleeding nipple, it may be vomited or passed in the stool, and haemorrhagic disease may be suspected. Bleeding from the vagina occurs a few days after birth in about 5 per cent. of normal female infants. This is a physiological phenomenon and has no relation to true haemorrhagic disease.

After excluding the cases of haemorrhage discussed above, there remains a group which appears to be a clinical entity and to which the name of haemorrhagic disease of the newborn has been given. So in the present paper only those cases have been included which conform to the following definition- spontaneous internal or external haemorrhage in the newborn infant in the absence of trauma, infection or other definite disease' (Clifford).

\section{Present investigation}

One hundred and sixty-seven cases of haemorrhage in the newborn infant (excluding frank intracranial haemorrhage) were admitted to the medical wards of the Royal Hospital for Sick Children from January, 1931, to February, 1942, and the study of their records forms the basis of this report; eighteen have been examined personally. From the total twenty-one have been excluded for the following reasons:-

Fourteen because of infection.

Two cases of haemorrhagic enteritis.

Two cases with pneumonia.

Two cases of septicaemia.

Six cases with umbilical sepsis.

Two cases with septic infection of the skin.

Four because of profuse haemorrhage following minor degrees of trauma. In one of these asphyxia was also a factor.

Three because of vaginal haemorrhage, but with no haemorrhage elsewhere.

In three of the infants excluded because of sepsis of the umbilical cord, the infection was so slight in extent that it was probably incidental, and in another excluded because of septicaemia, it is possible that the infection was superimposed on the haemorrhagic condition. He was a premature infant weighing $2.23 \mathrm{kgm}$. in whom melaena had been present from the second day. He was transferred to hospital on the eighth day because slight melaena persisted and because he began to vomit all his feeds. On admission to hospital the haemoglobin was 20 per cent. Eighty c.c. of blood were transfused at once, and on the ninth day there was no further bleeding, but the child continued to vomit. On the tenth day fever developed and a submaxillary swelling was seen. The infant died on the twelfth day and the autopsy findings were multiple abscesses in the lungs, scanty abscesses in the kidneys, septic spleen, a submaxillary abscess and petechiae in the small intestine. One case has been included which clinically had true haemorrhagic disease, and in which post-mortem examination revealed, in addition to gross haemorrhage into the bowel, a tentorial tear with subdural haemorrhage. There was a history of difficult instrumental delivery, which would explain the subdural haemorrhage but not the severe bleeding from the stomach and bowel. The haemoglobin fell to 30 per cent. and the red cells to 976,000 per c.mm. An unsuccessful attempt to transfuse the child 
was made and death occurred a few hours later. There were no signs of cerebral haemorrhage during life.

After excluding these twenty-one cases the following is an account of the remaining one hundred and forty-six infants who fell strictly within the bounds of the definition of the disease given above.

Age at onset. Haemorrhage began in the first three days of life in one hundred and twenty-eight cases (89 per cent.) and of these it began on the second day in sixty-four cases ( 44 per cent.). In table 1 is shown the age at onset in the cases of true haemorrhagic disease and in the cases of haemorrhage associated with infection. From this it will be seen that there is a tendency for the haemorrhage to have a later onset in the cases with infection than in those of true haemorrhagic disease, though four of the latter did not show any signs of bleeding until the eighth, tenth and twenty-first days of life in two others.

Two cases in which there was no evidence of haemorrhage clinically, but which showed haemorrhages at autopsy are not included in this table, as the age at onset is not known.

Sex incidence. There was a preponderance of females in this series, the figures being as follows: sixty-one males, eighty-three females, two unstated. That is 57 per cent. of cases occurred in female infants. Most other authors have found that the sex incidence was equal or that there was a slight preponderance of male infants.

Seasonal incidence. In the present series the disease was more prevalent in the first six months of the year than in the second. Ninety-four cases occurred between the months of January and June and fifty between July and December. McCollum (1928) reports a maximal incidence in January with a decrease in the number of cases from April to September. Salomonsen (1939) found that the disease was more prevalent in the winter and spring months (December to June) and draws attention to a similar seasonal incidence in the physiological prolongation of the clotting time in newborn infants. The significance of this seasonal variation and its possible relation to dietary deficiencies, or to infections of the mother during pregnancy, is not understood. There appears to be little difference between the diets of mothers of healthy infants and those of mothers whose infants develop haemorrhagic disease (Salomonsen, 1939; Kove and Siegel, 1940). In this series no details of the maternal diet during pregnancy are available. The mortality rate appears to be independent of seasonal influence.

Place in family. Thirty per cent. of cases occurred in first-born infants, but 25 per cent. occurred in those who occupied the fifth to the fifteenth place in the family. It would appear, therefore, that the place in the family does not influence the incidence of this disease. Other workers (Clark, 1933; Snedeker, 1941; Salomonsen, 1939) have shown an increased incidence in first-born infants.

Influence of abnormal pregnancy, labour or delivery. Details of the pregnancy, labour and delivery are in many cases scanty, and probably often inaccurate, as the history in all these cases was obtained from the father, a relative or a friend. Twelve per cent. of the mothers were delivered by forceps, 6 per cent. suffered from hypertensive toxaemia of pregnancy, and there was a history of prolonged labour in 5 per cent. Antepartum haemorrhage occurred in one case and in nine other cases there was a history of asphyxia at birth. Two of the mothers had twin pregnancies and in both cases one twin only was affected.

Site of bleeding. The commonest source of haemorrhage is from the alimentary tract. One hundred and thirty-five cases out of one hundred and forty-six had either haematemesis or melaena or both. One hundred and eight cases had bleeding from the alimentary tract alone, and six other cases came into this category during life, but at the autopsy showed evidence of 
HAEMORRHAGIC DISEASE OF THE NEWBORN

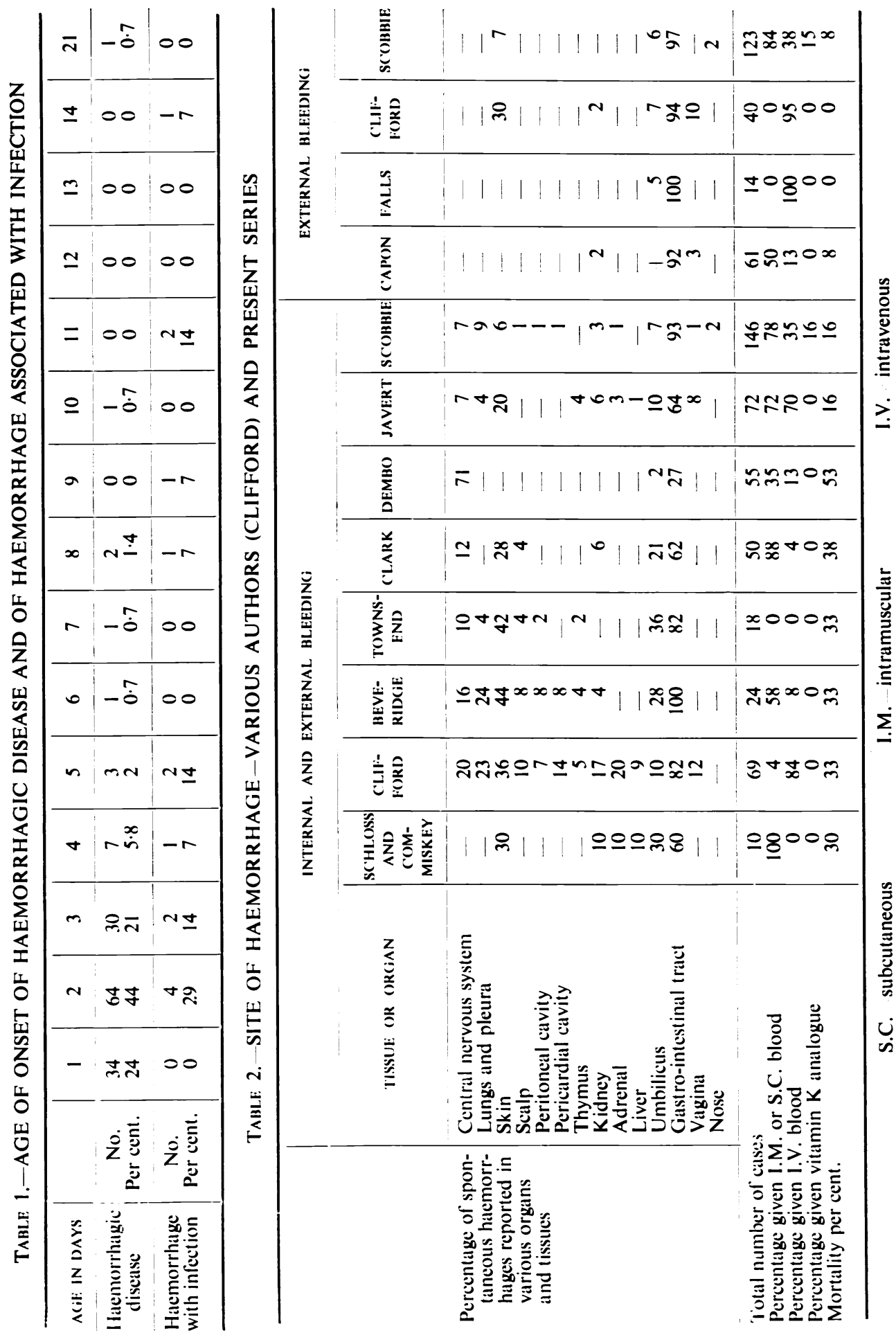


internal haemorrhage in addition. The bleeding varied in amount from small quantities of altered blood to large amounts of bright red blood in the vomitus or passed per rectum. In most other cases bleeding occurred from more than one site. Table 2 is a table constructed by Clifford (1935) with the addition of the findings observed in the present series. It gives the site of haemorrhage observed by Clifford himself and other workers. It will be seen that there is a marked correspondence between Javert's (1938) figures and those reported in this paper, but the incidence of internal haemorrhages is not as great, either in Javert's (1938) or in the present series, as that reported by other authors. Internal haemorrhage occurred in 42 per cent. of Clifford's (1935) cases as compared with 16 per cent. in the present series. It is possible that this difference is due in part to the fact that practically every infant in the present series was born at home, and not in a maternity hospital where complicated labour, instrumental delivery and asphyxia occur more frequently. Further, in eight of the fatal cases in the present series ( 33 per cent.), no post-mortem examination was made and it is probable that had permission for autopsy been granted in every case, the incidence of internal haemorrhage would have been somewhat higher, although still lower than that found by Clifford (1935), Townsend (1894), Beveridge (1928) and Clark (1933).

Anaemia. Red blood cell counts, or in the absence of marked jaundice, estimations of haemoglobin at frequent intervals are of great value in determining whether haemorrhage is continuing or has ceased, and in judging the effect of treatment. A sudden fall in the haemoglobin percentage may occur in a very short space of time and transfusion at this stage may be life-saving. The following four examples illustrate this.

Case $1 \mathrm{Hb} 90$ per cent. on admission, fell to 60 per cent. in 3 hours.

Case $2 \mathrm{Hb} 74$ per cent. on admission, fell to 43 per cent. in 6 hours.

Case $3 \mathrm{Hb} 74$ per cent. on admission, fell to 43 per cent. in 6 hours.

Case $4 \mathrm{Hb} 78$ per cent. on admission, fell to 40 per cent. in 7 hours.

The patient's general condition must be taken into account along with the degree of anaemia as depicted by examination of the capillary blood. The haemoglobin percentage and the red cell count drops as the blood volume is restored following haemorrhage, and the interpretation of these figures is therefore modified by the rapidity of this reaction. The figures quoted suggest that restoration of blood volume may occur rapidly, but in one premature infant whose alimentary tract at autopsy was found to be full of blood, and who must have suffered severe blood loss, the haemoglobin shortly before death was 120 per cent. This patient suffered from internal haemorrhage in addition to haemorrhage into the lumen of the bowel and was very collapsed. There is no doubt that a certain number of deaths is caused by exsanguination. In 19 per cent. of the fatal cases examined post mortem no other cause of death was found.

Bleeding time. The bleeding time was determined in eleven cases. In two severe cases it was ten-and-a-half and five-and-a-half minutes respectively, and in the remaining nine cases it fell within normal limits. It should be remembered that prolongation of the bleeding time may occur in healthy newborn infants and in other conditions than haemorrhagic disease. For example, one case of haemorrhage associated with a severe furunculosis had a bleeding time of nine minutes.

Prothrombin content of the blood. Observations on the prothrombin content of the plasma have been made in fifteen definite cases of haemorrhagic disease of the newborn, and in three cases of haemorrhage associated with infection. Reid's (1941) modification of Quick's method for determining prothrombin was used in every case. A few micro-prothrombin tests were also performed, 
but details of these are not included as the results were found to be unreliable. The determination of the prothrombin content of the plasma by Quick`s method is dependent on the clotting time of recalcified plasma in the presence of an excess of thromboplastin. The clotting time estimated in this way is called the prothrombin time, and is found to be prolonged in cases with deficient prothrombin. It is not, however, a direct estimation of concentration of prothrombin, but serves as a measure of two factors concerned in coagulation, the prothrombin content of the plasma and its rate of conversion into thrombin. At each estimation the prothrombin time of normal plasma is first determined, and that of the patient's plasma is expressed as a percentage of the normal. This is known as the prothrombin index (Illingworth, 1939).

$$
\text { Prothrombin index }=\frac{\text { Normal prothrombin time }}{\text { Patient`s prothrombin time }} \times 100
$$

In the present series the prothrombin indices on admission to hospital and before treatment was commenced, have been charted in fig. 1, and the cases

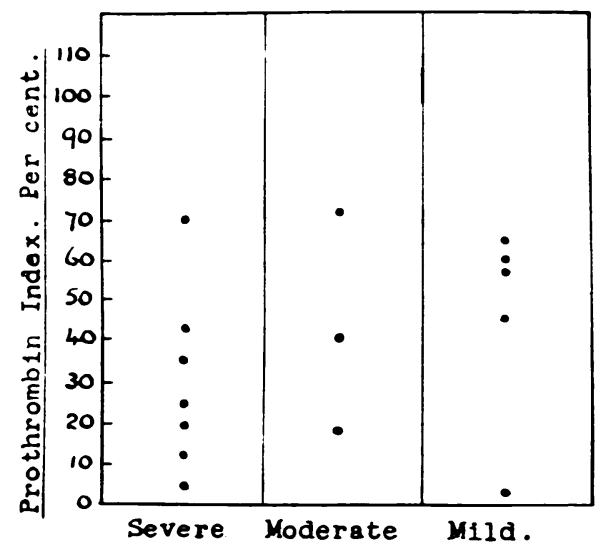

Fig. 1.-Prothrombin index in haemorrhagic disease.

have been grouped into three categories, severe, moderate and mild, depending on the extent of bleeding as judged by the haemoglobin percentage. Infants with haemoglobin over 100 per cent. were classified as mild, those with haemoglobin between 80 and 100 per cent. as moderate and those with haemoglobin less than 80 per cent. as severe. Seven cases fell into the severe, three into the moderate and five into the mild category. The onset of haemorrhage in these cases occurred on the first day in four cases, the second day in seven cases, the third day in four cases. For purposes of comparison fig. 2 shows the prothrombin indices of seventy-five healthy newborn infants on the first three days of life, twenty-five for each day. These infants were chosen from the healthy babies born in the Royal Maternity Hospital, Glasgow. From the figure it is seen that six cases ( 24 per cent.) on the first day, three cases (12 per cent.) on the second day and two cases ( 8 per cent.) on the third day have prothrombin indices less than 50 per cent., but in none of these was there any evidence of haemorrhage. While ten of the fifteen cases of haemorrhagic disease had prothrombin indices below 50 per cent., five cases, one severe, one moderately severe and three mild, had indices of 70 per cent., 73 per cent., 65 per cent., 60 per cent. and 59 per cent. respectively. The prothrombin indices in the three cases excluded because of infection were 26,12 and 62 per cent.

Morbid anatomy. Twenty-four deaths occurred in the series, giving a mortality rate of 16.4 per cent. Sixteen of the twenty-four cases were examined 
post mortem. Haemorrhage into the bowel was found in twelve cases, into the lungs and pleura in eleven, into the brain and meninges in four, into the peritoneal cavity in two and from the umbilicus in two. Haemorrhage was also noted once into each of the following organs, the kidney, suprarenal, pericardium, nose, vagina and ear. In only one case was there any evidence of ulceration of the stomach or bowel. In this case small erosions were found in the gastric mucosa. Haemorrhage into the bowel was the only positive finding in 19 per cent. of the cases which were examined post mortem.

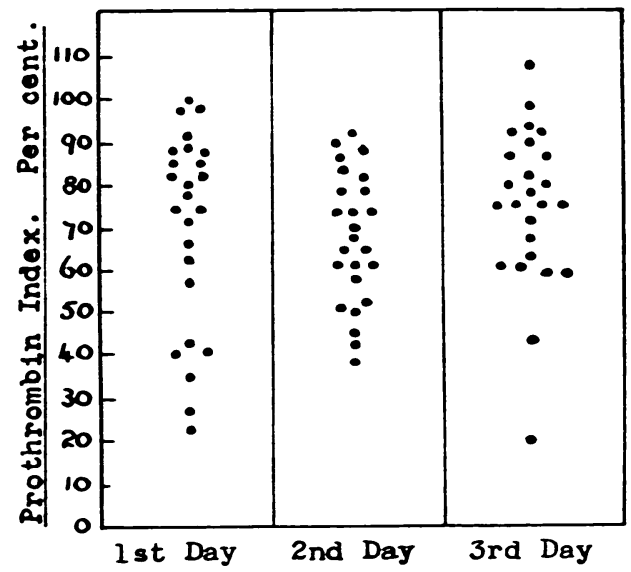

FIG. 2.-Prothrombin index in normal newborn infants.

Treatment. A great variety of remedies has been employed in the treatment of haemorrhagic disease, among others, perchloride of iron, ergotin, tannin, adrenaline and gelatin, but it is probable that none of them is of any real therapeutic value. About thirty years ago Schloss and Commiskey (1911) advocated intramuscular or subcutaneous injection of blood, and till recently this form of treatment, fortified in severe cases with blood transfusion, has supplanted the older methods. Recently, however, doubt has been thrown on the efficacy of blood injection, and with increased knowledge of the etiology of the disease, vitamin $\mathbf{K}$ has become the popular remedy. In a critical review of the subject, Clifford (1935) questions the value of all therapeutic agents. From a study of this review and of the reports of other workers, it is extremely difficult to make a true evaluation of the various methods advocated. The chief difficulty arises in the fact that there is great difference of opinion regarding the definition of the disease. Another difficulty arising out of this is the wide range of figures quoted for the mortality rate in untreated cases (35 to 84 per cent.), whilst the fact that transfusion, though not necessarily a specific remedy, is certainly a life-saving measure in exsanguinated infants, adds to the confusion.

The recent work on the rôle of vitamin $\mathrm{K}$ and prothrombin in haemorrhagic states has led to the assumption that deficiency of the latter is the cause of haemorrhagic disease of the newborn. Evidence in favour of this view is not conclusive, for prothrombin may be very deficient in infants who show no signs of haemorrhage, and conversely haemorrhage may occurs in infants with a relatively high plasma prothrombin (fig. 1 and 2). If, on the other hand, low prothrombin is the primary cause of the haemorrhage, then there can be little doubt that the administration of vitamin $K$ is the most effective method of raising it to the normal level. In fig. 3 are shown the results of giving (a) subcutaneous blood and (b) a vitamin $K$ analogue to normal newborn infants. From this it will be seen that the administration of vitamin $\mathrm{K}$ promptly raised the prothrombin index to between 85 and 115 per cent., whereas the subcutane- 
ous injection of blood had little effect. This confirms the work of Sanford and Leslie (1938) and of Lawson (1941) that subcutaneous injections of blood do not raise the plasma prothrombin. For obvious reasons it has been impossible to ascertain the effect of transfusion on the concentration of plasma prothrombin in normal infants, but in table 3 , which gives the prothrombin index before and after treatment in nine cases of haemorrhagic disease, it will be seen that in four (no. 3, 4,5 and 6) there was a definite rise in its level after transfusion. From this table it will also be seen that of two cases given subcutaneous blood (no. 1 and 2) one showed a definite rise twenty hours after the injection while no significant change occurred in the other. Of four cases (no. 7, 8, 9 and 10) treated with vitamin $K$ analogue only, all showed a definite rise in the prothrombin index, but there may be a delay in its action as in two of the cases

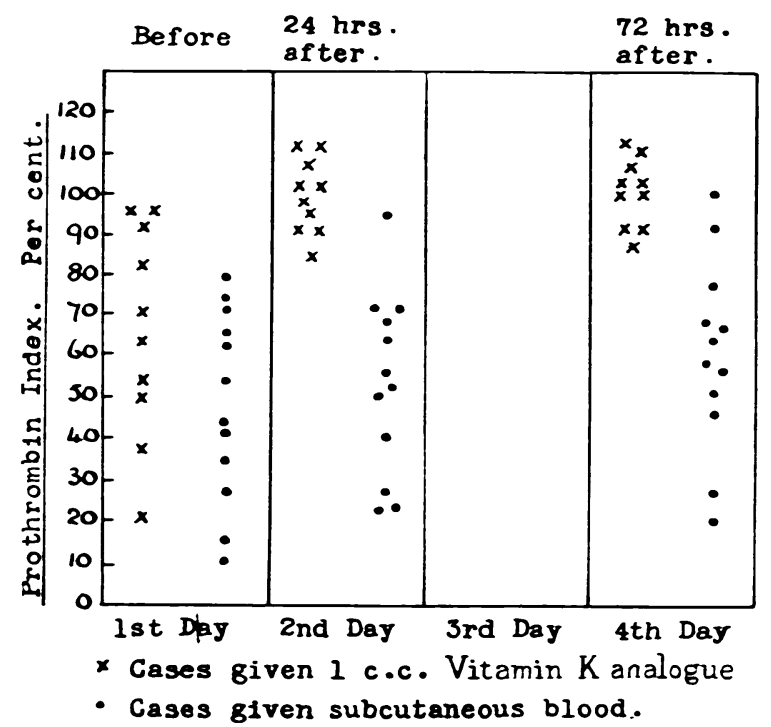

FIG. 3.-Changes in the prothrombin index after giving subcutaneous blood or vitamin $\mathrm{K}$ to normal newborn infants.

the rise in the index did not occur till between sixteen and twenty-four hours after its administration.

In the present investigation three methods of treatment have been employed: (1) subcutaneous or intramuscular injections of blood; (2) intravenous blood; (3) vitamin $\mathrm{K}$. In thirty-seven cases treatment by blood transfusion was combined with the injection of blood subcutaneously or intramuscularly, and in eight cases it was given with vitamin $K$.

It is difficult to estimate the relative value of different methods of treatment in a disease in which spontaneous recovery is known to occur when blood loss is slight, and so an attempt has been made to classify the cases according to their severity, as judged by the percentage of haemoglobin on admission to hospital or later, if a lower reading was obtained. As blood examinations were not always carried out in the earlier years included in this review, a certain number of cases remain unclassified. Table 4 shows the results of treatment of one hundred and thirty-six infants. Ten of the series of one hundred and forty-six cases have been excluded for the following reasons. Two were dead on admission to hospital, two were moribund, four were cases of internal haemorrhage not diagnosed during life, and two were so mild that treatment was withheld. From this table it will be seen that of the fifty-one cases treated 
by blood transfusion three died (5.9 per cent.), while of the seventy given subcutaneous blood alone, twelve died (17.1 per cent.) and of the fifteen given vitamin $\mathrm{K}$ alone, one died (6.6 per cent.). Excluding those unclassified, of the fifty cases treated by transfusion forty-four were severe as compared with twenty of the fifty-four classified cases given subcutaneous or intramuscular blood only. Taking this factor into account it would appear that intravenous injection of blood is far superior as a therapeutic measure to subcutaneous or intramuscular injections. Owing to the relatively small number of cases treated with vitamin $\mathrm{K}$ it is difficult to draw definite conclusions from the figures given in table 4 , but as only three deaths occurred in forty-four severe cases treated by blood transfusion compared with one death in the group of six severe cases treated with vitamin $\mathrm{K}$ alone, and as six other severe cases treated by the latter method required blood transfusion in addition, it would seem that blood transfusion is more effective as a therapeutic agent than vitamin $\mathrm{K}$ particularly in severe cases. Comparisons of the mortality in cases treated by vitamin $K$ and by subcutaneous or intramuscular injections of blood are again limited in value by the small number of cases in the vitamin $\mathbf{K}$ group. Of the fifteen cases treated by the latter method one died, and of the seventy cases given blood injections twelve died, whereas the proportion of severe cases was slightly higher in the vitamin $\mathrm{K}$ group. Consideration of these results suggests that blood transfusion is the most efficacious method of treatment, next in order of merit comes vitamin $\mathbf{K}$, and last subcutaneous or intramuscular injection of blood. Against the universal use of blood transfusion is the fact that it is a procedure which requires special technique and skill, while the administration of blood by subcutaneous or intramuscular injection and the intramuscular injection of a vitamin $K$ analogue require no special skill and are devoid of danger.

\section{Discussion}

When trauma and infection are excluded, the problem arises as to the cause of the spontaneous haemorrhage characteristic of this disease. It has been stated that prothrombin deficiency, which causes a delay in the clotting time of the blood, is the sole etiological factor (Quick and Grossman, 1940). The prothrombin indices in the cases examined in this series compared with those of healthy control infants of the same age, do not give striking evidence in favour of this claim. One would expect the prothrombin index in every case of haemorrhagic disease to be lower than in physiological hypoprothrombinaemia; and relatively lower in severe than in mild cases. That this does not occur is shown in fig. 1 and 2 . These findings confirm earlier statements that prolongation of the clotting time is found in only a proportion of cases of haemorrhagic disease. Moreover, unless prothrombin has some function other than that of blood coagulation, it is difficult to understand why blood, whose clotting power is poor, should cause spontaneous haemorrhage, since the function of blood coagulation is not called into play until the closed system of vessels, in which the blood circulates, is broken. If, however, there should be a break in that system, deficiency of plasma prothrombin will no doubt be the cause of a greater quantity of blood escaping than one would expect from the size of the break. The hypothesis favoured by Snelling (1940), Mengert (1940), Kove and Siegel (1940), that there are other factors besides hypoprothrombinaemia, seems to be the most likely one. The favourable results 
HAEMORRHAGIC DISEASE OF THE NEWBORN
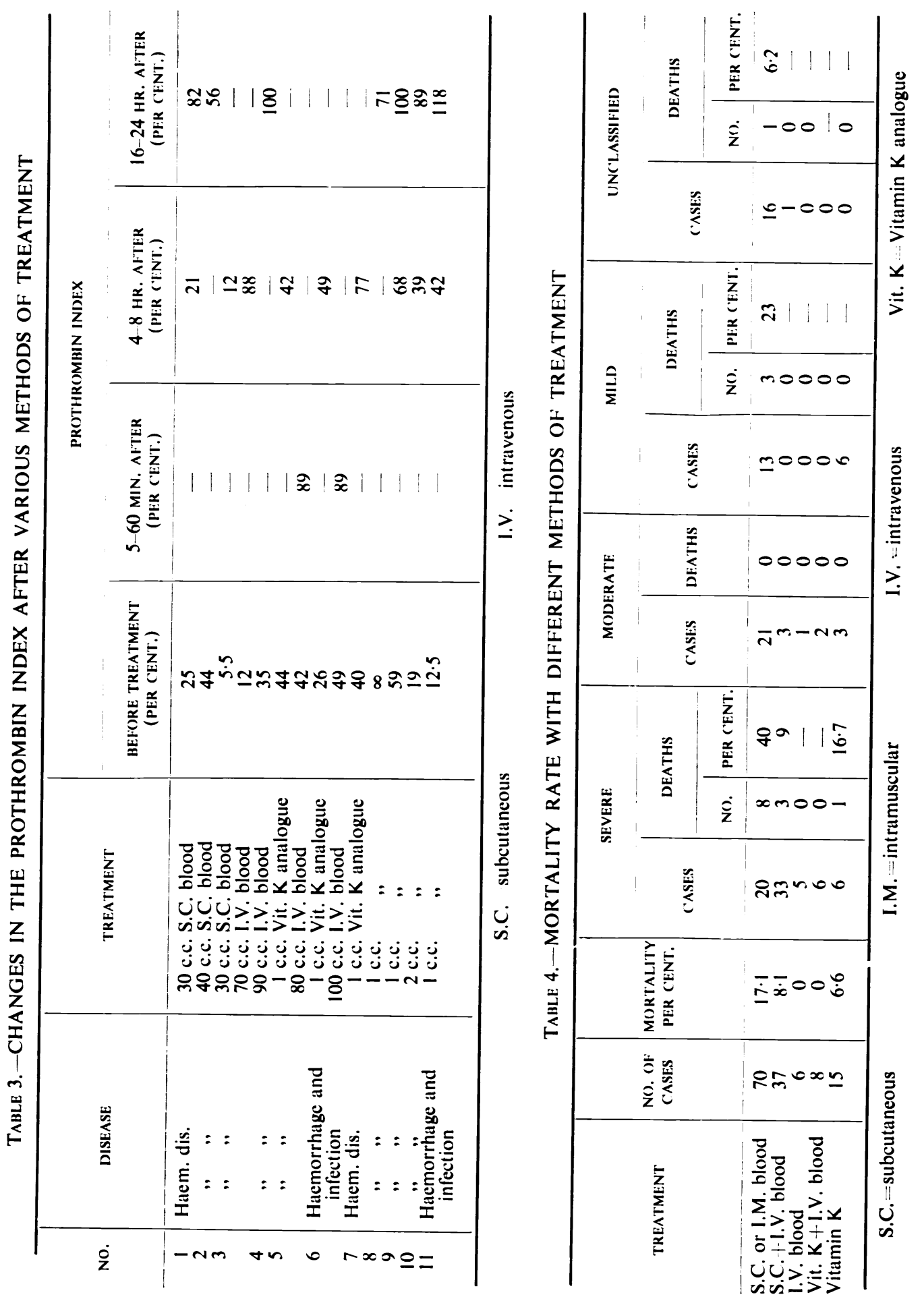

을

言

믐

त्र

$\overrightarrow{0}$

$\vec{\omega}$

ఖ

$\stackrel{7}{2}$

in

जे 
obtained by treatment with vitamin $\mathrm{K}$, however, suggest that hypoprothrombinaemia is an important factor in the etiology of the disease. In this connexion it has been shown that hypoprothrombinaemia of the newborn can be prevented by the antenatal administration of vitamin $\mathrm{K}$ to the mother (Hellman, Shettles and Eastman, 1940; Snelling, 1940), though it has as yet not been proved that such treatment causes a significant reduction in the incidence of haemorrhagic disease of the newborn.

\section{Summary}

1. The definition of haemorrhagic disease of the newborn is discussed.

2. One hundred and forty-six cases admitted to the Royal Hospital for Sick Children, Glasgow, between January, 1931, and February, 1942, are analysed.

3. The rôle of vitamin $\mathrm{K}$ and prothrombin deficiency in the etiology of the disease is discussed.

4. The effects of treatment by subcutaneous or intramuscular injections of blood, by blood transfusion, and by vitamin $\mathrm{K}$ are compared.

Thanks are due to Professor G. B. Fleming, Professor J. Hendry and Dr. Stanley Graham for giving facilities for carrying out the work and for helpful advice and criticism. Part of the expenses of the investigation were defrayed by a grant from the Medical Research Council.

\section{REFERENCES}

Beveridge, R. S. (1928). Arch. Dis. Childh., 3, 39.

Capon, N. B. (1932). Lancet, 2, 887.

Clark, F. H. (1933). Arch. Pediat., 50, 482.

Clifford, S. M. (1935). J. Pediat., 14, 333.

(1941). Ibid., 18, 567.

Cruickshank, J. N. (1923). Lancet, 1, 836.

Dembo, L. H. (1933). Amer. J. Obstet. Gynec., 25, 587.

Hellman, L. M., and Shettles, L. B. (1939). Johns Hopk. Hosp. Bull., 65, 138.

,-- , and Eastman, N. J. (1940). Amer. J. Obstet. Gynec., 40, 844.

Illingworth, C. F. W. (1939). Lancet, 1, 1031.

Javert, C. T. (1938). Amer. J. Obstet. Gynec., 35, 200.

Kove, S., and Siegel, H. (1940). J. Pediat., 17, 448.

Lawson, R. B. (1941). Ibid., 18, 224.

MacPherson, A. I. S. (1941). Brit. med. J., 2, 433.

McCollum, J. L. (1928). Canad. med. Ass. J., 18, 550. Quoted by Salamonsen.

Mengert, W. F. (1940). Amer. J. Obstet. Ginec., 40, 844.

Quick, A. J., and Grossman, A. M. (1940). Amer. J. med. Sci., 199, 1.

Reid, J. (1941). Brit. med. J., 1, 579.

Von Reuss, A. R. (1921). The diseases of the newborn, London, 443.

Rodda, F. C. (1920). J. Amer. med. Ass., 75, 452.

Salomonsen, L. (1939). Acta paediatr., Stockh., 27, Supp. 1, 5.

Sanford, H. N., Shinigelsky, I., and Chapin, J. M. (1942). J. Amer. med. Ass., 118, 697.

Sanford, N. S., and Leslie, E. I. (1938). J. Pediat., 12, 16.

Schloss, O. M., and Commiskey, L. J. J. (1911). Amer. J. Dis. Child., 1, 276.

Snedeker, L. (1941). J. Pediat., 19, 1.

Snelling, C. E. (1940). Ibid., 17, 615.

Townsend, C. W. (1894). Arch. Pediat., 11, 559. 